\title{
How do Danish community pharmacies vary in engaging customers in medicine dialogues at the counter - an observational study
}

\author{
Susanne KAAE, Sahdia SALEEM, Maria KRISTIANSEN.
}

Received (first version): 25-Feb-2014 Accepted: 15-Aug-2014

\begin{abstract}
${ }^{*}$
Background: Counter counseling is an important part of community pharmacies service delivery. Difficulties arise because customers appear less interested than the staff in discussing their medicine. It is unclear how individual pharmacies differ with regard to overcoming these obstacles.

Objective: This study explores differences in the communication practices of pharmacies with regard to engaging customers in medicine dialogues.

Methods: The work of Stevenson et al. describing five types of interaction scenarios at the counter was used for structured overt non-participant observations of 100 encounters in each of five Danish pharmacies. Variation in pharmacies success in engaging customers in medicine dialogues were calculated using descriptive statistics, and the statistical significance of observed differences across pharmacies was analyzed using odds ratios (OR). Results: Considerable differences between the pharmacies were identified. Differences exist in how often pharmacy staff attempts to encourage customers to participate in medication dialogues and how often they succeed. The pharmacies serving the most customers per day were the most successful. A possible link between a low number of refill customers offered counseling and 'success rate' was identified.

Conclusions: The pharmacies showed considerable variation in attempts to engage customers in medication dialogues at the counter and success in doing so. The reasons for the identified patterns are unclear.
\end{abstract}

Keywords: Counseling; Health Communication; Community Pharmacy Services; Professional Practice; Observation; Denmark

\section{INTRODUCTION}

Communication at the pharmacy counter is important for community pharmacies to expand their core function of medication supply. Obstacles in adopting such activities have been observed as customers appear less interested than the pharmacy staff in discussing their medications. ${ }^{1,2}$

Communication research has so far mainly aimed at characterizing the type of information provided by staff, numbers of questions asked etc., but have not specifically explored how staff actually manages to engage customers in medicine dialogues. ${ }^{3-5}$

In 2012, a master thesis conducted at the University of Copenhagen found that staff's engagement of customers in medicine dialogues depended on the type of purchased medicine and that refill prescription customers more often than other customers decline offers of medicine dialogues. ${ }^{6}$

Pharmacies have shown differences in recruitment of patients for cognitive services at the counter and similarly variation in provision of advice regarding the use and effect of the medicine. ${ }^{7,8}$ It is therefore likely that pharmacies also vary in engaging customers in medicine dialogues. To increase the insight into this phenomenon we explored on basis of the data of the master thesis of 2012, whether pharmacies vary in engaging customers in medicine dialogues at the counter.

\section{METHODS}

\section{Framework}

To explore how individual pharmacies manage to engage customers in medicine dialogues, the work of Stevenson et al., which exactly describes five types of interaction scenarios regarding pharmacies' engagement of customers (if engagement was attempted by staff and what was the customers' response to this attempt), was used as a theoretical basis to construct coding schemes for observations in Danish community pharmacies. ${ }^{9}$

* Susanne KAAE. PD (pharm). Associate Professor, Department of Pharmacy, Faculty of Health and Medical Sciences, Copenhagen University. Copenhagen (Denmark). susanne.kaae@sund.ku.dk

Sahdia SALEEM, MSc (pharm). Department of Pharmacy, Faculty of Health and Medical Sciences, Copenhagen University. Copenhagen (Denmark).

sahdia_s786@hotmail.com

Maria KRISTIANSEN. PhD. Associate Professor, Health Sciences Department, College of Arts and Sciences, Qatar University. Doha (Qatar); and Danish Research Centre for Migration, Ethnicity, and Health, Faculty of Health and Medical Sciences, University of Copenhagen.

Copenhagen (Denmark). maria.kristiansen@qu.edu.qa
Using an operationalized form of Stevenson's categories, we conducted a pilot study to assess the need to modify the framework for our study. Hence, two times three hours observation was conducted in one randomly chosen pharmacy. Subsequently, it was decided to add a new category that represented customers who purchased a specific product without the staff or the customer trying to initiate a dialogue about the medicine. Further, we merged the two categories of 'standardized 
dialogues' and 'other dialogues in which the staff encouraged participation and the customer cooperated' as we in practice found it difficult to distinguish between these.

The final types of staff-customers interactions were:

- The customer wants a particular product and does not want to engage in any discussion.

- The customer wants advice, and the staff member cooperates.

- The staff member encourages participation, and the customer cooperates.

- The staff member encourages participation, and the customer does not cooperate (the customer explicitly indicates he does not find counseling relevant).

- The customer wants a particular product, and neither the staff member nor the customer encourages participation.

The 'success rate' was defined as the sum of encounters where "the customer wants advice, and the staff member cooperates" and "the staff member encourages participation, and the customer cooperates"; both are examples of interactions which resulted in some dialogue about medicine. Similarly the 'failure rate' was calculated, defined as the sum of encounters of "the customer wants a particular product and does not want to engage in any discussion" and "the staff member encourages participation, and the customer does not cooperate"; both options are examples of interactions where the customer refused a medicine dialogue.

The type of purchased medicine was also registered, as this aspect has been found important for the customer's response, and divided into the following categories: ${ }^{6}$

- Purchase of a specific over-the-counter (OTC) product (e.g., asking for a specific OTC product)

- Purchase of an unspecified OTC medicine (e.g., wanting something for headache)

- Purchase of a first time prescription medicine

- Purchase of a refill prescription medicine

- Purchase of both OTC and prescription medicine

\section{Observations}

Overt non-participant structured observations were deemed the most appropriate method. A short observation distance was required in the pharmacies (1-2 meters) for the researcher to register the necessary information. A total of 100 encounters were observed over 1-2 days in each pharmacy of customers purchasing either prescription and/ or OTC medicine. We included both pharmacists and pharmacy technicians because they are both engaged in counter counseling in Denmark. Observations were conducted randomly across different pharmacy counters. When more than one customer was being served, the single observer shifted systematically between customers and staff members at different counters in order to ensure representativity of observations. Observations were conducted during busy and quiet times in the pharmacy. Customers were orally informed about the study by staff, and no customers declined participation. The observations were conducted in November and December 2011.

\section{Sampling of participatory pharmacies}

A purposive sampling frame was set to compare communication of individual pharmacies. To avoid selection bias, the sampling frame included small and large pharmacies (defined by numbers of prescriptions per day) as well as pharmacies located in the capital either centrally or marginally; and pharmacies in provincial and rural areas as earlier studies have suggested that these parameters influence counseling. ${ }^{8,10}$ Rural areas were defined as pharmacies located in cities with less than 10.000 inhabitants and provincial as pharmacies located in cities with more than 10.000 inhabitants.

Five different pharmacies that met the sampling criteria were sent a letter of invitation and received a follow-up telephone call. Three pharmacies agreed to participate, and two declined. Two additional pharmacies were contacted to obtain a relatively even representation of pharmacies located both within the capital as well as provincial/ rural areas, and both agreed to participate, see Table 1.

\section{Analysis}

To explore the variation of pharmacies' engagement of customers, all numerical data were entered into Microsoft Excel. The percentage of 'success rate' and 'failure rate' for each pharmacy were calculated. The percentages were calculated in relation to each other i.e. to the encounters where either customer or staff displayed a particular interest or disinterest in a medicine dialogue, in order to understand the difference between succeeding and failing (in contrast to none of the parties trying to initiate a dialogue at all). 'Success rate' and 'failure rate' variation across pharmacies relating to the type of purchased medicine were then calculated using descriptive statistics. The statistical significance of observed differences across the five included pharmacies was analyzed using odds ratios (OR) to measure the probability of successful engagement of customers (event) in relation to type of pharmacy (exposure). The ORs given below thus express the differences in achievement of successful counseling according to pharmacy using the highest scoring pharmacy as control and the remaining four pharmacies as cases. A stringent $p$-value of $\leq 0.05$ denoted statistical significance, and $95 \%$ confidence intervals are given for each OR. As the purpose of the study was to detect types of differences between individual pharmacies in their communication practices rather than linking such behavior to specific factors such as size and

\begin{tabular}{|c|c|c|}
\hline \multicolumn{3}{|c|}{ Table 1. Size and location of pharmacy } \\
\hline $\begin{array}{c}\text { Size (number of customers } \\
\text { served daily at the pharmacy } \\
\text { counter) }\end{array}$ & Location \\
\hline 1 & 500 & Suburb to capital \\
\hline 2 & 1000 & Suburb to capital \\
\hline 3 & 1000 & Centre of capital \\
\hline 4 & 300 & Rural \\
\hline 5 & 350 & Provincial \\
\hline
\end{tabular}


location, these parameters were not directly included in the statistical analysis.

\section{Ethics}

According to the Danish Data Protection Agency ethical permission for this study was not required because no personal data from the customers were registered.

\section{RESULTS}

The study included a total of 500 encounters, representing a random selection of customers. A total of 304 of the observed customers were females, and 196 were males; 278 customers were below 50 years old, and 222 were over 50 years old.

\section{Considerable difference in 'success rate'}

The average 'success rate', i.e., obtaining medication dialogues across all five types of medication purchases, varied considerably between the five pharmacies and ranged from $54 \%$ (pharmacy 1) to $82 \%$ (pharmacy 3 ); see Table 2. Notably and unexpectedly (not being the purpose of the study), the two pharmacies with the absolute highest 'success rates' (pharmacy 2 (76\%) and pharmacy $3(82 \%)$ ) were also the pharmacies that served the most customers per day; see table 1 and 2. Very few variations between the pharmacies were identified for customers purchasing first time prescription medicine, and unspecified OTC medicine. On the contrary, large differences were observed for purchase of a specific OTC product and refill prescription medicine. The 'success rate' of specified OTC medicine varied from $45 \%$ (pharmacy 1) to $84 \%$ (pharmacy 3 ), and the rate of refill prescription medicine from $23 \%$ (pharmacy 5 ) to $57 \%$ (pharmacy 2 and 3 ).

The difference in average 'success rate' between pharmacies was significant when testing the highest scoring pharmacy (pharmacy 3 ) against the other pharmacies, see Table 3. Pharmacy 3 showed significant better communication pattern skills compared to pharmacy $1 \quad(\mathrm{OR}=3.8807[95 \% \mathrm{Cl}$ 2.04: 7.39] and $5(\mathrm{OR}=2.6755[95 \% \mathrm{Cl} 1.39: 5.14]$ but not compared to pharmacy 2 (OR= $1.4386[95 \%$ $\mathrm{Cl}$ 0.72: 2.86] and $4(\mathrm{OR}=1.7716[95 \% \mathrm{Cl} 0.91$ : 3.47].

\section{Pharmacies that less frequently ask have higher 'success rate'}

The percentage of encounters where neither the staff member nor the customer tried to initiate a dialogue varied from $12 \%$ (pharmacy 1 ) to $38 \%$ (pharmacy 2), see Table 2. The two pharmacies with the highest 'success rate' (pharmacy 2 and 3) were the pharmacies where staff most frequently abstained from attempting to engage the customer in a medication dialogue (pharmacy 2 (38\%) and pharmacy $3(33 \%))$. This difference could not only be explained by pharmacies avoiding engaging refill prescription customers. Pharmacy 2 asked at least as many refill customers as pharmacy 4 (pharmacy 2 (23 customers) and pharmacy 4 (21 customers)). Pharmacy 3 did, however, have the lowest identified number of refill customers whom they tried to encourage to participate in a medication dialogue $(\mathrm{No}=14)$. Notably, pharmacy 1 had the lowest

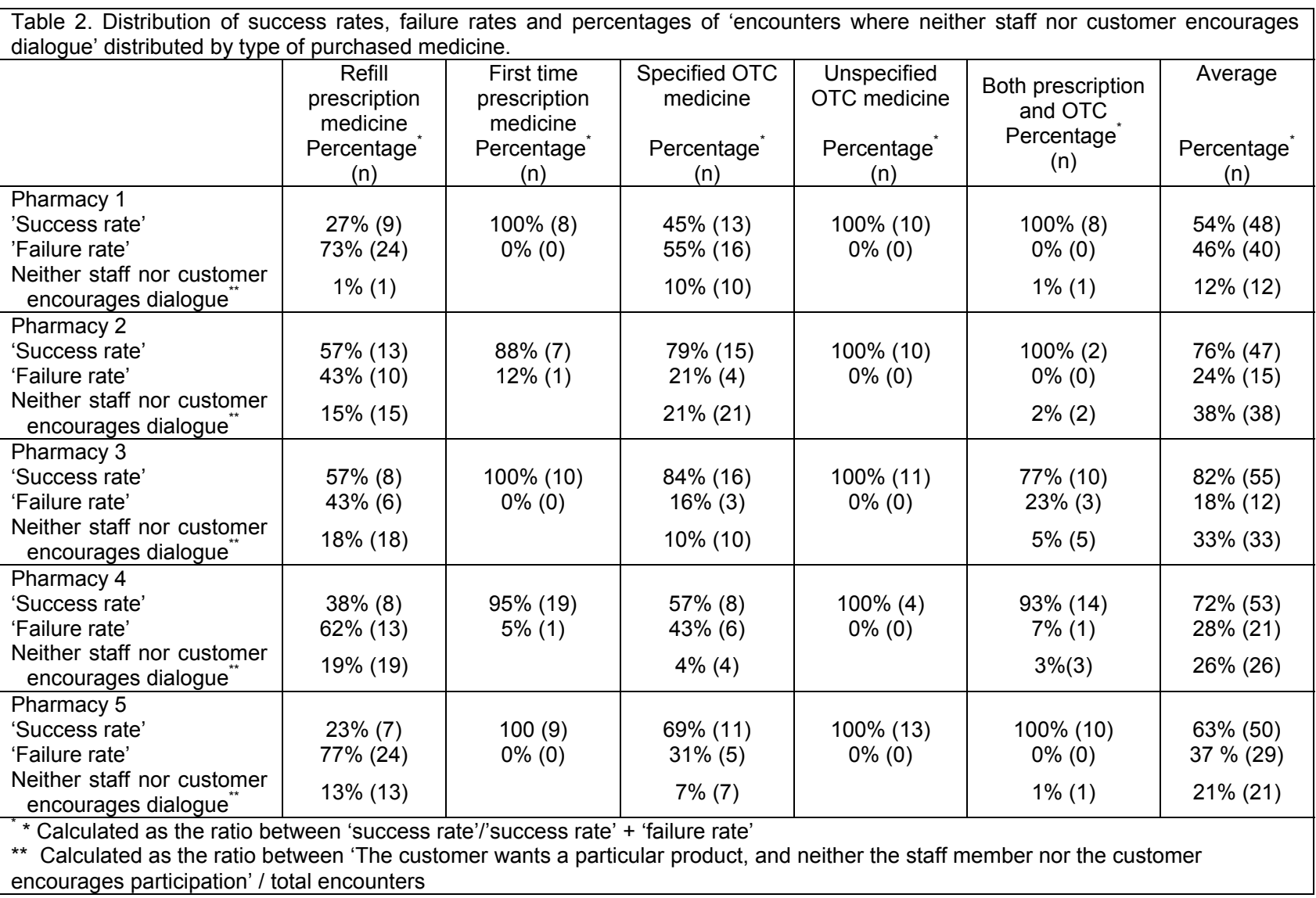




\begin{tabular}{|l|c|c|c|c|c|}
\hline Table 3. Differences between average 'success rate'/ 'failure rate' between pharmacies. Pharmacy 3 used as control. \\
\hline & Pharmacy 3 & Pharmacy 1 & Pharmacy 2 & Pharmacy 4 & Pharmacy 5 \\
\hline 'Success rate' & 82 & 54 & 76 & 72 & 63 \\
\hline 'Failure rate' & 18 & 46 & 24 & 28 & 37 \\
\hline OR $(95 \% \mathrm{Cl})$ & & 3.8807 & 1.4386 & 1.7716 & 2.6755 \\
& & $(2.0378-7.3903)$ & $(0.7243-2.8573)$ & $(0.9052-3.4671)$ & $(1.394-5.1352)$ \\
\hline
\end{tabular}

average 'success rate' (54\%) and invited nearly all refill prescription customers to engage in medication dialogues $(\mathrm{No}=33 / 34)$.

\section{DISCUSSION}

This study identified considerable differences between community pharmacies in the numbers of attempts by pharmacy staff to encourage especially refill prescription customers' participation in medication dialogues at the counter and their success in doing.

\section{Strengths and limitations}

Significant variations in pharmacies' engagement of customers were observed with a two to four-fold higher probability of achieving a successful medication dialogue comparing the highest scoring pharmacy (pharmacy 3) to pharmacy 1 and 5 respectively. No significant differences were observed for the two remaining pharmacies but the results nevertheless confirmed the assumption that communication practices of individual pharmacies vary. Although the study is limited by its sample size and observational design, this variation should be taken into consideration when investigating and trying to improve these practices as the reasons for these differences are still unclear.

As the study showed that variation between pharmacies regards only specific customer groups, the representation of such groups and possible differences between pharmacies in dealing with them ought to be studied further. Similarly, the specific type of purchased refill prescription medicine could play a role; other studies have showed that staff counseling behavior depended on the type of prescription medicine purchased. ${ }^{7,8}$

The results hinted a possible link between size of pharmacy and 'success rate' - however the study was too small and inadequately designed to made distinct conclusions in this regard. Besides, the Hawthorne effect might have generated too positive results regarding the number of customers that staff tried to engage in dialogues. ${ }^{11}$

\section{The influence of size and location}

A possible link to the size of the pharmacy was identified. Tully et al. in contrast concluded that the number of prescriptions per day did not influence pharmacy counseling. ${ }^{7}$ Vainio et al. showed that large pharmacies located in commercial centers informed customers more often about the use of medicine than small, however also found that these pharmacies inform more often compared to rural pharmacies. ${ }^{8}$ This contrasts the findings of Xu et al. who found that rural pharmacies provided more counseling than urban located pharmacies and partly to Ranelli et al. who found that pharmacists in small cities initiated more medicine dialogues. ${ }^{12,13}$
Puspitasari showed that metropolitan pharmacies gave more verbal information, and rural pharmacies provided more written information. ${ }^{10}$ Hence, the literature regarding the influence of pharmacy size and location is inconclusive perhaps due to the reason that there are relatively few studies in the area which often explores different practice aspects. However, the possibility that size and location are not primer influential factors of counseling, but rather the culture of the pharmacy including the leadership style of the owner, also exist. ${ }^{14,15}$

\section{The link between refill customers and 'success rate'}

The findings indicated that pharmacies with less pharmacy staff invitations to refill prescription customers had higher 'success rates'. Abstaining from encouraging refill customers in dialogues could either be considered to be a conservative or a selective communication strategy. Pharmacy 2 and 4 had similar scores regarding the ratio of refill prescription customers that staff abstained from encouragement however the 'success rate' differed considerably. This particular result indicates that quality aspects also play a role and that these differ between the pharmacies. According to the literature, future studies in this regard might benefit from studying staff follow-up techniques; a Scottish study found that staff asked questions but failed to tailor their counseling accordingly. ${ }^{16}$ Studying the interaction at the counter as a ritual has also been recommended. $^{17}$

\section{CONCLUSIONS}

The pharmacies varied in both their trying to and succeeding in engaging customers in medication dialogues at the counter. This study has proven the value of studying pharmacy communication at an individual pharmacy unit level.

\section{CONFLICT OF INTEREST}

The authors declare no conflict of interest.

\section{COMO VARÍAN LAS FARMACIAS \\ COMUNITARIAS DANESAS AL ATRAER DIÁLOGOS SOBRE MEDICAMENTOS EN EL} MOSTRADOR - ESTUDIO OBSERVACIONAL

\section{RESUMEN}

Antecedentes: El consejo de mostrador es una parte importante de la provisión de servicios en farmacias comunitarias. Las dificultades aparecen porque los clientes parecen estar menos interesados que el personal en discutir sobre sus medicamentos. No está claro cómo se diferencian las farmacias para superar estos obstáculos.

Objetivo: Este estudio explora las diferencias en las prácticas de comunicación de farmacias en relación a atraer clientes a diálogos sobre medicamentos. 
Métodos: Se usó el trabajo de Stevenson et al. que describe cinco tipos de escenarios de interacción en el mostrador para 100 observaciones estructuradas, abiertas y sin participación de encuentros en cinco farmacias danesas. Se calculó mediante estadística descriptiva la variación en el éxito en atraer clientes a diálogos sobre medicamentos, y la significación estadística de las diferencias encontradas se analizó usando odds ratios (OR).

Resultados: Se identificaron diferencias considerables entre las farmacias. Existían diferencias en la frecuencia en que el personal de la farmacia intenta animar a los clientes a participar en diálogos sobre la medicación y en la frecuencia en que tenían éxito. Las farmacias que atendían más clientes por día tenían más éxito. Se identificó un posible nexo entre un bajo número de clientes a los que se les ofrece consejo y la 'tasa de éxito'.

Conclusión: Las farmacias mostraron variaciones considerables en los intentos de atraer clientes a diálogos sobre medicación en el mostrador y en el éxito en hacerlo. Las causas de los patrones identificados son inciertas.

Palabras clave: Consejo; Comunicación en Salud; Servicios de Farmacia Comunitaria; Práctica Profesional; Observación; Dinamarca

References

1. Assa-Eley M, Kimberlin CL. Using interpersonal perception to characterize pharmacists' and patients' perceptions of the benefits of pharmaceutical care. Health Commun. 2005;17(1):41-56.

2. Kaae S, Traulsen JM, Nørgaard LS. Challenges to counseling customers at the pharmacy counter - why do they exist? Res Social Adm Pharm. 2012 May-Jun;8(3):253-257. doi: 10.1016/j.sapharm.2011.05.002

3. Murad MS, Chatterley T, Guirguis LM. A meta-narrative review of recorded patient-pharmacist interactions: Exploring biomedical or patient-centered communication? Res Social Adm Pharm. 2014;10(1):1-20. doi: 10.1016/j.sapharm.2013.03.002

4. Puspitasari HP, Aslani P, Krass I. A review of counseling practices on prescription medicines in community pharmacies. Res Social Adm Pharm. 2009;5(3):197-210. doi: 10.1016/j.sapharm.2008.08.006

5. Schommer JC, Wiederholt JB. The association of prescription status, patient age, patient gender, and patient question asking behavior with the content of pharmacist-patient communication. Pharm Res. 1997;14(2):145-151.

6. Kaae S, Mygind A, Saleem S. Characterization of the current communication patterns in Danish community pharmacies - an observational study. Res Social Adm Pharm. 2013;9(6):958-964. doi: 10.1016/j.sapharm.2012.10.003

7. Tully MP, Beckman-Gyllenstrand A, Bernsten CB. Factors predicting poor counseling about prescription medicine $\mathrm{i}$ Swedish community pharmacies. Patient Educ Couns. 2011;83(1):3-6. doi: 10.1016/j.pec.2010.04.029

8. Vainio KK, Airaksinen MS, Hyykky TT, Enlund KH. Effect of the therapeutic class on counseling in community pharmacies. Ann Pharmacother. 2002;36(5):781-786.

9. Stevenson FA, Leontowitsch M, Duggan C. Over-the-counter medicines: professional expertise and consumer discourses. Sociol Health IIIn. 2008;30(6):913-928. doi: 10.1111/j.1467-9566.2008.01108.x

10. Puspitasari HP, Aslani P, Krass I. How do Australian metropolitan and rural pharmacists counsel consumers with prescriptions? Pharm World Sci. 2009;31(3):394-405. doi: 10.1007/s11096-009-9289-9

11. McCambrigde J, Witton J, Elbourne DR. Systematic review of the Hawthorne effect: New concepts are needed to study research participation effects. J Clin Epidemiol. 2014;67(3):267-277. doi: 10.1016/j.jclinepi.2013.08.015

12. Ranelli PL, Coward RT. Residential differences in the use of pharmacists by older adults and their communication expreinces with pharmacists. J Rural Health. 1996;12(1):19-32.

13. Xu T, Rojas-Fernandez $\mathrm{CH}$. Ancillary community pharmacy services provided to older people in a largely rural and ethnically diverse region: a survey of customers in West Texas. J Rural Health. 2003;19(1):79-86.

14. Desselle SP, Tipton DJ. Factors contributing to the satisfaction and performance ability of community pharmacists: a path model analysis. J Soc Adm Pharm. 2001;18(1):15-23.

15. Doucette WR, Jambulingam T. Pharmacy entrepreneurial orientation: antecedents and it's effect on the provision of innovative pharmacy services. J Soc Adm Pharm. 1999;16(1):26-37.

16. Garner $M$, Watson MC. Using linguistic analysis to explore medicine counter assistants' communication during consultation for nonprescription medicines. Patient Educ Couns. 2007;65(1):51-57.

17. Shah B, Chewning B. Conceptualizing and measuring pharmacist-patient communication: a review of published studies. Res Social Adm Pharm. 2006;2(2):153-185. 